\title{
ORIENTAÇÃO NA EDUCAÇÃO A DISTÂNCIA: UMA ANÁLISE DA REALIDADE BRASILEIRA
}

\author{
Andreia de Bem MACHADO ${ }^{1}$ \\ Andreza Regina Lopes da SILVA ${ }^{2}$ \\ Viviane SARTORI ${ }^{3}$ \\ Fernando José SPANHOL ${ }^{4}$
}

\begin{abstract}
Doutoranda em Engenharia e Gestão do Conhecimento. Universidade Federal de Santa Catarina. andreiadebem@gmail.com

Doutoranda em Engenharia e Gestão do Conhecimento. Universidade Federal de Santa Catarina. andrezalopes.ead@gmail.com

Doutoranda em Engenharia e Gestão do Conhecimento. Universidade Federal de Santa Catarina. vivi.sartori19@gmail.com

Professor do Programa de Pós-Graduação em Engenharia e Gestão do Conhecimento. Universidade Federal de Santa Catarina. profspanhol@gmail.com
\end{abstract}

Recebido em: 28/05/2014 - Aprovado em: 17/09/2014 - Disponibilizado em: 15/12/2014

\begin{abstract}
Resumo: Comunicar é um desafio assim como uma necessidade encontrada ao longo da história da humanidade em seus diferentes espaços sociais. No processo educacional não é diferente. Independe da modalidade educacional é preciso haver comunicação para ocorrer o ato de ensinar e aprender. A luz deste cenário o presente artigo visa refletir sobre o papel do professor no processo de orientação em trabalhos de conclusão de curso oferecido em cursos de pósgraduação na modalidade a distância que conta com o apoio das Tecnologias da Comunicação Digital para potencializar a efetividade deste processo. Para atender o objetivo proposto neste artigo trabalhou-se com uma busca na literatura e também documental que seguiu para aprofundamento com um estudo de caso comparativo entre duas instituições brasileiras de ensino, uma de caráter público e outra privada, tendo como ênfase o processo de produção de trabalhos de conclusão de curso em programas de pós-graduação na modalidade a distância.
\end{abstract}

Palavras-chave: Orientador. Educação a Distância. Ambiente Virtual de Ensino-aprendizagem.

\section{GUIDANCE IN DISTANCE EDUCATION: AN ANALYSIS OF THE BRAZILIAN REALITY}

\begin{abstract}
Report is a challenge as well as a need found throughout the history of mankind in their different social spaces. In the educational process is no different. Independent of educational modality there needs to be communication to the act of teaching and learning occur. The light of this scenario, this article aims to reflect on the teacher's role in the guidance for completion of course work offered in postgraduate courses in distance mode which has the support of Digital Technologies Communication process for enhancing the effectiveness of this process. To meet the objective proposed in this paper worked with a search in the literature and also for deepening documentary that followed with a comparative case study between two Brazilian institutions, one public and one private character, with the emphasis on the production process of work completion of course in graduate programs in distance mode.
\end{abstract}

Keywords: Teacher. Distance Education. Ambient virtual teaching-learning. 


\section{INTRODUÇÃO}

A Educação a Distância (EaD) em sua essência atuando como prática social na disseminação do conhecimento tem crescido e atingido diferentes lugares onde antes $\mathbf{o}$ conhecimento ainda era limitado ou mesmo impossibilitado. No Brasil a $\mathrm{EaD}$ ainda é uma ação que pode ser considerada nova apesar de vir se consolidando dia a dia. Esta constatação tem aferindo crescente interesse e investimento de instituições públicas e privadas principalmente as de nível superior por meio de cursos de graduação ou pósgraduação. Leite Filho e Martins (2006) complementam esta reflexão ao apontar que as atividades de pós-graduação no Brasil tem sido impulsionada pela necessidade de titulação dos docentes universitários e sua correspondente qualificação como pesquisadores. Contudo, apesar de pesquisas apontarem o crescimento do número de pósgraduandos, esta área ainda é bastante desafiada quando se reflete mais profundamente sobre a pós-graduação.

Considera-se que esta situação é potencializada devido ao descumprimento de normas e procedimentos que tratam sobre o regimento dos cursos, seguido da falta de preparo ou mesmo de tempo de professores para realizem a atividade de orientação realizada principalmente no trabalho de conclusão do curso.
Contudo a formação hoje é elemento indissociável da sociedade do conhecimento e esta crescente demanda pela busca da formação tem impulsionado a demanda da oferta de Curso de Pós-graduação e, consequentemente, aumento no número de trabalhos de conclusão de curso. A preocupação com a qualidade no processo de orientação destes trabalhos são elementos que motivaram esta pesquisa. Castro (1979), já nos anos de 1970, indagou sobre a problemática da orientação nos cursos de pósgraduação apontando fragilidades no processo de orientação. Vinte e quatro anos depois, Berndt (2003) corroborou com as argumentações de Castro, apontando que, no cotidiano dos Cursos de pós-graduação, a questão mais relevante estava no processo de orientação, pois considera que “[...] orientadores com competência e experiência são poucos, diante da demanda contínua por orientação de trabalhos científicos" (BERNDT, 2003, p. 2).

Apesar das críticas no Brasil, a Coordenação de Aperfeiçoamento de Pessoal de Nível Superior (CAPES) tem apontado alguns critérios de avaliação e indicadores quantitativos da produção discente dos programas, de modo a minimizar a fragilidade deste processo, por exemplo: tempo médio de titulação, quantidade de alunos por professores, percentuais de titulação e desistências. Neste sentido considera-se que, 
apesar de questões como estas, tendo no cerne a eficiência de um programa de pósgraduação, poderem ser pesquisadas e acompanhadas dentro das próprias universidades como indicadores de qualidade dos programas, na prática, sua existência é precária. Freitas (2002) aponta que é a fase da elaboração dos trabalhos de conclusão de curso uma das mais difíceis para os alunos, contudo apesar da relevância do tema o autor indica que pesquisas que analisam ou discutem a questão da orientação, bem como o relacionamento entre orientador e orientando, são escassas.

Sendo assim, neste artigo tem-se como

\section{EaD: UM OLHAR A LUZ DO PROCESSO DE ORIENTAÇÃO}

A sociedade do conhecimento é impulsionada pela necessidade de capacitação continuada tanto nos aspectos tecnológicos e/ou conceituais. Essa necessidade esta atrelada ao conjunto de elementos que nos cercam na concretização de diferentes atividades, e que representam a circulação constante da diversidade de informações disponibilizadas no contexto da sociedade atual. A tecnologia é um dos artefatos potenciais de nossa atualidade, estando ligada ao conjunto de atividades do nosso dia-a-dia, a uma diversidade de pessoas, em distintos espaços e em tempos diferentes, e ainda a um processo objetivo analisar o papel do orientador no processo de elaboração do trabalho de conclusão de curso considerando o cenário educacional de pós-graduação ofertado na modalidade de EaD no Brasil. Para tanto esta pesquisa caracteriza-se como exploratória, descritiva, estudo de caso analisado numa abordagem qualitativa organiza em um quadro descritivo, comparativo elementos relevantes de análise entre duas instituições: instituição A (pública) e instituição B (privada), considerando a realidade de ambas no que tange ao processo de comunicação (orientando e orientador) em um dado curso realizado na modalidade a distância.

de formação no qual a $\mathrm{EaD}$ vem ganhando espaço e atenção. $\mathrm{O}$ amplo acesso aos diversos níveis educacionais, representados por crianças, adolescentes e adultos, tende a colaborar para a ampliação econômica e cultural, do contexto social em que vive.

Dessa forma, considera-se que a educação é um processo que possibilita o crescimento social, cultural e econômico das distintas representatividades do contexto social. É a educação o motivador para a o crescimento sociocultural e, é dada esta representatividade do conhecimento, que acesso aos ambientes educacionais vem sendo repensados e resignificados. Hoje muitos já estão sendo organizados pelas salas de aulas virtuais onde o ambiente de ensino-aprendizagem vem 
sendo inseridos de modo a permitir que o ensinar e o aprender possam acontecer em diversos níveis, espaços geográficos e temporais. Esta é uma realidade que vem sendo potencializada pela $\mathrm{EaD}$, num contexto inovador devido a inserção das Novas Tecnologias de Informação e Comunicação (NTIC), contribuindo assim com os processos de formação do indivíduo, não tendo como objetivo substituir modelos de ensinar e aprender.

Seja na modalidade a distância ou mesmo no modelo de ensino tradicional o cenário atual exige mais do que nunca o repensar do processo. Moore e Kearley (2007, p. 2) chamam atenção para a relevância de se atentar, já no início do planejamento educacional, durante a criação do curso, para o processo de "[...] comunicação por meio de várias tecnologias e disposições organizacionais e administrativas especiais" de modo que possa se potencializar a comunicação entre os atores envolvidos no processo.

As ferramentas que fazem a interligação entre a comunicação entre sujeitos baseiam as distintas formas de comunicação apontadas por Lévy (1999), tendo como destaque três formas, a saber: olho no olho; uma para muitos; e muitos para muitos.

É neste processo de comunicação intensivo que ocorre a orientação em trabalhos de conclusão de cursos em programas de pósgraduação mediado intensivamente na $\mathrm{EaD}$ pelas tecnologias digitais de comunicação e auxiliado por artefatos metodológicas como livros, atividades de pesquisa, relato de vivências, exploração do contexto sócio histórico e cultural presente, dentre outros.

$\mathrm{Na} \mathrm{EaD}$, principalmente no processo de orientação a trabalhos acadêmicos de pósgraduação, é primordial que exista o empenho contínuo entre os sujeitos envolvidos nesse processo, estes representados por orientandos, orientadores, equipe técnica, equipe de tutoria, equipe de coordenadores.

Outro fato muito importante dentro do processo de orientação diz respeito ao relacionamento entre orientando e orientador como uma relação a ser construída de modo a potencializar o processo de ensinoaprendizagem. Considera-se que primeiramente o orientador deve ter, obrigatoriamente, conhecimento na área de pesquisa escolhida pelo seu orientando e também apresentar interesse pelo tema proposto por esse. É relevante também que seja estabelecida uma empatia entre orientador e orientando, pois a orientação será bem mais efetiva se existir a cooperação entre as partes. Roesch (1996) complementa a discussão apontando aspectos negativos que influenciam no processo de orientação, como: a inexistência ou poucas leituras e reflexões 
sobre o tema da sua pesquisa e também a falta de organização de tempo para realizar o trabalho de conclusão de Curso.

De acordo com Freitas (2001) o orientador e o orientando devem ter uma relação de confiança mútua para que o orientador possa indicar a trilha das pedras de modo a vencer os desafios e consolidar o seu processo de aprendizagem. Logo, não deve apenas o orientador esperar a submissão dos orientandos e nem o orientando dar consentimento a tudo o que o orientador apontar ou indicar. $\mathrm{O}$ respeito e afeição devem ser mútuos e em seriedade de modo que o trabalho de conclusão de curso seja realizado em parceria já que a “(...) aprovação do orientador é fundamental em todos os sentidos: acadêmicos, burocráticos e afetivos." (FREITAS, 2001, p. 24).

Para uma efetiva orientação é necessário que orientando e orientador comunique-se constante e periodicamente com o intuito de sanar dúvidas desse processo e também superar dificuldades que vão surgindo ao longo do desenvolvimento do trabalho acadêmico. Esse elo e encontros só serão possíveis se houver uma relação de sintonia e de simpatia entre orientando e orientador. $\mathrm{O}$ respeito mútuo e admiração e afinidade que tornaram esses momentos agradáveis $\mathrm{e}$ essências para ambos.

No processo de orientação é crucial a discussão entre orientando e orientador para que esses possam organizar pensamento, falas, ações para proporcionar enriquecimento na pesquisa acadêmica. Assim, o processo de orientação, em tese, “(...) consiste basicamente numa leitura e numa discussão conjuntas, num embate de ideias, de apresentação de sugestões e críticas, de respostas e argumentações" (SEVERINO, 2002, p. 78). Considera-se que esses momentos possibilitam a elucidação a respeito do conteúdo e da forma.

Marques (2002, p. 231) considera que orientar “(...) significa ajudar o orientando a descobrir o que quer investigar, delimitando seu tema/hipótese de trabalho (...)". Com a orientação é possível reelaborar-se o caminho de pesquisa, a organização e planejamento do sumário que irá definir os rumos preliminares, do escrever que é cíclico e deve permitir a reescrita constante. Percebe-se que é fundamental que o orientador leia o trabalho do seu orientando para que conheça o que está sendo produzido e, assim, possa auxiliar com intervenções que possibilitem a elaboração de conceitos pertinentes à pesquisa levando o orientando a produzir seus próprios saberes, com autonomia e competência.

A comunicação é fundamental para a interação do processo ensino-aprendizagem. No momento final dos cursos de pósgraduação não é diferente, pelo contrário, a 
orientação, principalmente a distância, exige uma comunicação fluídica e intensiva.

O processo basilar da comunicação nos diz que para haver comunicação é necessário que uma mensagem seja comunicada entre emissor e receptor. No processo educacional tem-se dois atores essenciais que hora atuam como emissor hora como receptor, já que na sociedade do conhecimento o orientador, como o próprio nome sugere, é quem orienta o processo, mas diferente do século passado não é mais com a visão singular de ser o detentor do conhecimento.

$\mathrm{Na} \mathrm{EaD}$ os encontros entre orientando e orientador, geralmente acontecem virtualmente, em tempo e espaço distintos. A comunicação ocorre sem lugar definido, como elucida Kenski (2004): Na Ead, o fluxo de mensagens para o compartilhamento do conhecimento pode estar exposta apenas na tela do computador permitindo novas formas de comunicação.

Intercedendo essa analogia temos a mensagem e as informações a serem difundidas. Essa ligação deve ir além da transmissão de uma mensagem, pois a comunicação deve permitir o "partilhar sentido." (LÉVY, 1999, p. 147).

No processo de orientação em trabalhos de conclusão de cursos, principalmente em programas de pós-graduação, objeto de estudo desta pesquisa, na modalidade a distância, esses momento são geralmente por um Ambiente Virtual de Ensino-Aprendizagem (AVEA) aqui representados por dois software específicos. São eles:

\section{O Modular Object Oriented Distance}

Learning (Moodle) um software livre que proporciona o gerenciamento para criação de curso online. É muito utilizado por diferentes instituições de ensino por ser um software gratuito, bastante intuitivo e de fácil modelagem.

O webct (Web Course Tools) um software pago que também possibilita a criação de cursos online. É uma ferramenta tecnológica bastante similar o moodle, porém pouco utilizada pelas instituições de ensino, por ser um instrumento que não é gratuito.

O AVEA permite que a comunicação seja intensificada, principalmente em cursos oferecidos a distância contribuindo com usabilidade do curso.

O enfoque dessa pesquisa será analisar o orientador no processo de orientação de trabalhos de conclusão de curso no cenário da EaD considerando um estudo de caso comparativo realizado entre instituição pública e privada de modo a se analisar também a comunicação dentro do espaço onde ocorrem as interações entre orientando e orientador, nesse caso o ambiente virtual de aprendizagem. 


\section{PROCEDIMENTOS METODOLÓGICOS}

Com o objetivo de refletir sobre o papel do orientador no processo de orientação em trabalhos de conclusão de curso em programas de pós-graduação na modalidade a distância $\quad \mathrm{o}$ procedimento metodológico adotado para esta pesquisa descritiva e exploratória iniciou-se com uma busca da literatura que seguiu com uma análise documental com abordagem qualitativa dos dados permitindo elaborar-se um quadro comparativo entre a prática de comunicação no processo de orientação de trabalho de conclusão de curso entre uma instituição A (privada) e B (pública).

No tocante dessa pesquisa, a fonte documental, é representada pelo registro escrito das interações estabelecidas entre professor e aluno, no AVEA. Esses registros foram selecionados e analisados, com base nas interações assíncronas. Quanto ao AVEA, a sua representatividade compreende as plataformas Moodle e Webct, que exercem o suporte para os cursos de especialização e mestrado, vinculados a uma instituição pública e uma privada de ensino, no Brasil.

$\mathrm{Na}$ universidade $\mathrm{A}$ analisada, utiliza-se a plataforma Moodle e na universidade B utiliza-se a plataforma Webct. Na tabela 1 a seguir faz-se uma breve comparação entre recursos comumente utilizados em cursos a distância considerando as duas plataformas em análise.

Tabela 1 - Relação de artefatos utilizados na Webct e Moodle

\begin{tabular}{|c|c|c|}
\hline $\begin{array}{c}\text { Critérios } \\
\text { para } \\
\text { Análise }\end{array}$ & $\begin{array}{c}\text { Plataforma Moodle } \\
\text { Universidade A } \\
\text { (Instituição Pública) }\end{array}$ & $\begin{array}{c}\text { Plataforma Webct } \\
\text { Universidade B } \\
\text { (Instituição } \\
\text { Privada) }\end{array}$ \\
\hline Fórum & Sim & Sim \\
\hline Chat & Sim & Não \\
\hline $\begin{array}{c}\text { Postagem da } \\
\text { Etapa }\end{array}$ & Sim & Sim \\
\hline $\begin{array}{c}\text { Mensagens } \\
\text { Suporte } \\
\text { Tutores }\end{array}$ & Sim & Não \\
\hline $\begin{array}{c}\text { Suporte de } \\
\text { Materiais }\end{array}$ & Nim & Não \\
\hline $\begin{array}{c}\text { Manual- } \\
\text { Elaboração de } \\
\text { Monografia }\end{array}$ & Sim \\
\hline \multicolumn{2}{|c|}{ Fonte: Elaborada pelos autores } \\
\hline
\end{tabular}

Não existe na plataforma Webct, utilizado na universidade privada, fóruns para interação assíncrona durante o processo de elaboração do trabalho de conclusão de curso, apesar de a plataforma disponibilizar este recurso. Já na universidade pública é disponibilizado um fórum para cada etapa da elaboração do trabalho de conclusão de curso.

O orientando terá a sua disposição cinco etapas a cumprir durante o processo de orientação, a saber:

Tabela 2 - Etapas do processo de orientação

\begin{tabular}{|c|l|}
\hline Etapas & \multicolumn{1}{|c|}{ Atividades } \\
\hline Primeira & $\begin{array}{l}\text { Introdução, justificativa, problema, } \\
\text { objetivo geral e objetivos específicos }\end{array}$ \\
\hline Segunda & Revisão da literatura e metodologia \\
\hline Terceira & Resultados e conclusões \\
\hline Quarta & Postar a versão para defesa \\
\hline Quinta & $\begin{array}{l}\text { Acompanhamento da última etapa, } \\
\text { postagem da versão final após } \\
\text { avaliação da banca }\end{array}$ \\
\hline
\end{tabular}

Fonte: Elaborada pelos autores

A apresentação do trabalho, geralmente, é 
realizada por meio de webconferência, ou seja, um momento virtual e envolve orientador, orientando e dois professores avaliadores.

Todas as etapas ocorrem um prazo específico de 15 dias para entrega da mesma. No fórum de cada etapa acontece varias interações assíncronas. Durante este período de construção do trabalho de conclusão de curso a comunicação tem uma necessidade intensiva de se realizar e de acordo com as instituições pesquisadas para intensificar e potencializar este momento, algumas vezes diferentes recursos comunicacionais podem ser inseridos no processo, como, o uso do Skype e do chat. Neste sentido apesar de ambas as plataformas disporem do recurso, apenas a instituição A (pública) relatou o uso em alguns momentos deste recurso para interação síncrona entre orientando e orientador.

Observou-se ainda durante o processo de orientação o uso do recurso de postagem que implica no envio pelo AVEA das etapas preliminares. Esta fase no Webct, na universidade privada, ocorre em quatro etapas intituladas: D0 (proposta inicial do trabalho final), D1 (proposta contendo o tema, objetivo geral e objetivos específicos), D2 (o trabalho final com todos os elementos estruturais de um trabalho de conclusão de curso).

Entre cada etapa existem os feedbacks entre orientador e orientando. $\mathrm{O}$ orientador nesse momento indica as diretrizes a serem realizadas pelo orientando. Com o fechamento do trabalho, posteriormente o orientando terá que fazer uma defesa do trabalho presencialmente no polo de apoio presencial. Na universidade pública como descrito anteriormente, há cinco etapas de postagem que são realizadas por meio de um fórum. Sendo que em cada etapa há os feedbacks entre orientador e orientando, no sentido de auxiliar o acadêmico na realização do seu trabalho final (monografia).

$\mathrm{Na}$ universidade $\mathrm{B}$ (privadas) há apenas professores-orientadores para o apoio e acompanhamento na fase da realização do trabalho de conclusão de curso. Já na universidade A (pública) existe também tutores para auxiliarem o orientador e o orientando na fase de elaboração da monografia. Percebeu-se ainda que por meio do Moodle a instituição A utiliza para ampliar e facilitar a comunicação o sistema de mensagem do software. Apesar de ambos ambientes virtuais disporem do recurso, a instituição B não indica o seu uso, o que pode ser um fator que comprometa a comunicação neste momento de orientação.

Outra observação feita nesta pesquisa foi quanto a participação do tutor, considerando os AVEA analisados, que apontou ser o tutor um ator que contribui significativamente neste processo facilitando a comunicação para uma 
construção efetiva do trabalho, principalmente no que tange a configuração, além de auxiliar o orientador na verificação da originalidade do trabalho acadêmico do orientando. Tudo isso é feito em ambas as instituições, porém na instituição A (pública) essa comunicação ocorre por meio dos recursos que o software disponibiliza, como o sistema de mensagem e fórum, por exemplo.

Também identificou-se que ambos os softwares analisados permitem a inclusão de materiais (conteúdo), contudo apenas a universidade A, com a plataforma Moodle, mostrou utilizar o recurso para este fim de orientação.

Outra observação diz respeito à falta de um manual de elaboração de trabalho de conclusão de curso. Apesar de as duas plataformas virtuais de ensino-aprendizagem ter suporte para que seja inserido um manual para o aluno identificou-se apenas na universidade A analisada a existência de um manual com este intuito. Esse manual, presente no AVEA da instituição A, é distribuído aos orientadores em uma capacitação realizada antes do início do processo de orientação propriamente dito. Apesar de considerar-se este elemento como um possível facilitador de comunicação no processo de orientação para trabalhos de conclusão de curso, este não esta presente na universidade B.

\section{CONSIDERAÇÕES FINAIS}

Com essa pesquisa pode-se perceber o papel do orientador no processo de orientação em trabalhos de conclusão de curso oferecido em cursos de pós-graduação na modalidade a distância exige um acompanhamento e comunicação efetiva que pode ser potencializada com o uso das tecnologias digitais de comunicação, como diferentes AVEAs.

Percebeu-se ainda que entre os diferentes tipos de comunicação ocorridas no AVEA tanto na Universidade A (pública), quanto na Universidade B (privada) há pouca comunicação síncrona, entre orientador e orientando. As interações ocorrem geralmente via mensagens realizadas no correio interno, por email e/ou mensagens postadas no AVEA caracterizando uma comunicação assíncrona o que em suma apresenta um período de tempo para receberem o feedback um do outro. No sentido de se evitar desencontros comunicacionais é importante que a linguagem utilizada dentro desse processo seja clara e objetiva para não haver "mau entendimento". É fundamental que o orientador saiba o que está falando, para quem está falando e como deve falar.

$\mathrm{Na}$ Universidade A (pública) foi possível perceber que essas interações assíncronas são realizadas através de mensagens e fóruns que 
são feitos em cada etapa do trabalho de conclusão de curso. Foi possível ainda perceber que ocorrem muitas interações síncronas realizadas através de recursos adicionais de comunicação, como o skype o que acaba proporcionando de acordo com relatos identificados por alunos e professores momentos enriquecedores, pois auxiliam e otimizam o tempo do orientando nos encaminhamentos a serem cumpridos para realização do seu trabalho final.

Estas observações nos permite identificar que a comunicação é elemento essencial no processo de ensino-aprendizagem e é potencializada quando permite interação. A comunicação síncrona ou assíncrona no processo de orientação é de suma importância no decorrer do curso para que se obtenha o sucesso desejado

Estas questões que permeiam a área da comunicação desde os primórdios da sociedade estão no cerne de muitas discussões educacionais, pois hoje a sociedade do conhecimento precisa se comunicar e conta com as tecnologias da comunicação digital para facilitar e intensificar este processo que na sua essência contribui para a formação do indivíduo seja ela na modalidade presencial ou a distância. Dada à relevância do tema e carência de pesquisas na área sugere-se intensificar a pesquisa no que diz respeito ao papel do professor na educação atual que vive um momento de expansão, ressignificação e inovação no cenário educacional. Vive-se hoje à luz de um mundo virtual.

\section{REFERÊNCIAS}

BERNDT, A. A questão da orientação na pósgraduação em Administração. Disponível em:<http://www.forvm.org.br/educarnav.html> Acesso em: 18 jan. 2014.

FREITAS, M. E. de.Viver a tese é preciso! Reflexões sobre aventuras e desventuras da vida acadêmica. Revista de Administração de Empresas, v. 42, n. 1, p. 88-93, 2002.

KENSKI, V. M. Tecnologia e Ensino Presencial a Distância. $6^{\mathrm{a}} \mathrm{ed}$. São Paulo: Papirus, 2004.

LEITE F, G. A; MARTINS, G. de A. Relação orientador-orientando e suas influências na elaboração de teses e Dissertações. REA, Edição especial, 2006.

MARQUES, M. O. A orientação de pesquisa nos programas de pós-graduação. In.

BIANCHETTI, L.; MACHADO NETTO, A. M. (Orgs.) A bússola do escrever: desafios e estratégias na orientação de teses e dissertações. Florianópolis: Ed. da UFSC, 2002.

MOORE, M; KEARSLEY, G. Educação a distância: Uma visão integrada. São Paulo: Thomson Learning, 2007.

PETERS, O. A educação a distância em transição: tendências e desafios. Trad. Leila Ferreira de Souza Mendes. Ed. Unisinos. São Leopoldo, RS. 2004.

ROESCH, S. M. A. Projetos de estágios do curso de Administração: Guia para Pesquisa, Projetos, Estágios e Trabalhos de Conclusão de Curso.São Paulo: Atlas,1996.

SANTOS FILHO, J. C.; CARVALHO, M. L. R. D. Orientação coletiva de mestrado na Faculdade de Educação da Unicamp. Caderno de Pesquisas, v. 78, p. 73-79, 1991.

SEVERINO, A. J. Metodologia do trabalho científico. 22. ed., São Paulo: Cortez, 2002. 